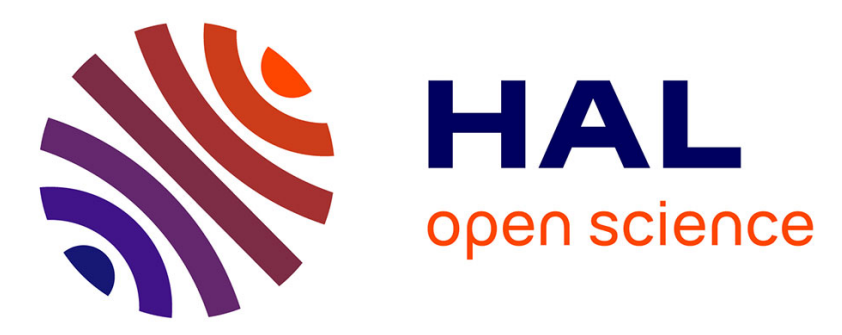

\title{
Sperm-depleted males influence the reproductive behaviour of conspecifics
}

Philippe Louapre, Stéphanie Llopis, Véronique Martel, Joan van Baaren

\section{To cite this version:}

Philippe Louapre, Stéphanie Llopis, Véronique Martel, Joan van Baaren. Sperm-depleted males influence the reproductive behaviour of conspecifics. Naturwissenschaften, 2014, 101, pp.875 - 882 . 10.1007/s00114-014-1227-6 . hal-01082953

\section{HAL Id: hal-01082953}

\section{https://hal-univ-rennes1.archives-ouvertes.fr/hal-01082953}

Submitted on 14 Nov 2014

HAL is a multi-disciplinary open access archive for the deposit and dissemination of scientific research documents, whether they are published or not. The documents may come from teaching and research institutions in France or abroad, or from public or private research centers.
L'archive ouverte pluridisciplinaire HAL, est destinée au dépôt et à la diffusion de documents scientifiques de niveau recherche, publiés ou non, émanant des établissements d'enseignement et de recherche français ou étrangers, des laboratoires publics ou privés. 
Sperm-depleted males influence the reproductive behavior of conspecifics

Philippe Louâpre ${ }^{1-2}$, Stéphanie Llopis ${ }^{2}$, Véronique Martel $^{3^{*}}$ and Joan van Baaren ${ }^{2 *}$

1- Biodiversity Research Centre, Earth and Life Institute, Université Catholique de Louvain, Belgium

2- UMR CNRS 6553 «Ecologie - Biodiversité - Evolution », Université de Rennes 1, France

3- Natural Resources Canada, Canadian Forest Service, Laurentian Forestry Centre, Canada

* These authors have contributed equally to the manuscript and are thus co-last authors.

philippe.louapre@mail-univscience.com

stephanie.1lopis@univ-rennes1.fr

veronique.martel@nrcan-rncan.gc.ca

joan.van-baaren@univ-rennes1.fr

Corresponding author: Philippe Louâpre

Biodiversity Research Centre, Earth and Life Institute

Université Catholique de Louvain

4-5, place Croix du Sud

B-1348 Louvain-la-Neuve, Belgium

Tel: $+(32) 10473492$

E-mail: philippe.louapre@mail-univscience.com 


\section{Abstract}

3 In many insect species, sperm-depleted males (SDMs, i.e. males that have exhausted their

4 sperm after a given number of matings) remain sexually active, and continue to mate females.

5 Here we investigated the behavioral modifications that occur in both sexes of the parasitoid

6 Asobara tabida Nees (Hymenoptera: Braconidae), after matings by fertile males and sperm-

7 depleted males. We show that (i) virgin females, mated females, and females mated to a

8 SDM exhibited different behaviors, and that (ii) males responded differently to females

9 depending on whether the females had previously mated with an SDM or not. Our findings

10 demonstrate that SDM influenced the reproductive behavior of both males and females,

11 especially with regard to male responsiveness and female attractiveness. These findings are

12 discussed in the context of adaptive behavior and fitness maximization in both males and

13 females.

\section{Keywords}

15 Sperm-depleted male, hymenopteran parasitoids, mate choice, Asobara tabida, conspecific 16 behavior 


\section{Introduction}

Sperm is not an infinite and free-cost resource to produce. In polygynous species, mating several females successively in a short period of time may result in sperm depletion: The sperm supply can be drained after a given number of females mated (Wedell et al. 2002). Sperm depletion can be temporary (in synspermatogenic species) or definitive (in prospermatogenic species), depending on the ability of males to produce new sperm during their adult life (Damiens and Boivin 2006; Boivin 2013). Sperm-depleted males (SDMs) have been found in many taxa, such as mammals (Preston et al. 2001), birds (Pizzari et al. 2003), lizards (Olsson et al. 2004), crustaceae (Rubolini et al. 2007) and fish (Smith et al. 2009). In insects, sperm depletion occurs in many species and SDMs individuals remain sexually active as they are still able to attract receptive females and to mate them (Simmonds 1953; Laing and Caltagirone 1969; Gordh and DeBach 1976; Assem et al. 1979; Nadel and Luck 1985; Ramadan et al. 1991; Ode et al. 1995; Damiens and Boivin 2005; Rönn et al. 2008; Steiner et al. 2008). It was suggested that continuing to mate is an adaptive strategy of SDMs to decrease the fitness of fertile males (Damiens and Boivin 2006). The authors indeed demonstrated that Trichogramma evanescens Westwood (Hymenoptera: Trichogrammatidae) females have a decreased ability to store sperm after being mated by SDMs (Damiens and Boivin 2006). To continue to mate is thus viewed as a SDMs' strategy to increase their relative fitness comparing to this of other males. On the other hand, such behavior may persist over generations because of the lack of selective pressure counter-selecting it (SDMs can obviously not produce progeny anymore). Whatever the adaptive significance of the SDM mating behavior, its effect on the behaviors of conspecifics (both males and females) remains largely unknown.

Females' behaviors may be modified after copulation; after mating, females usually become refractory to subsequent copulations for a given time, even without sperm transfer 
(Gillott 2003). This refractoriness to mating is caused by chemicals contained in the seminal fluids transferred during mating or by the male's behavior (Alcock 1994; Gillott 2003; Wedell 2005; Yamane 2013). The transfer of chemicals to the mated female is therefore viewed as a male strategy to suppress the subsequent reproductive activity of females, thus decreasing the likelihood of sperm competition (Ejima et al. 2007). For example, Radhakrishnan et al. (2009) showed that the transfer of seminal fluid in Bactrocera tryoni Froggatt (Diptera: Tephritidae) during mating induces female sexual inhibition. In this case, the behavior of the mated females is modified by SDM resulting in fewer opportunities for other males to access them. In many species, females mated to a SDM become less receptive to mating than virgin females, suggesting that these females no longer invest in pheromone biosynthesis after mating (Steiner et al. 2008). We however note that in at least another species, females mated to a SDM remain sexually active (Damiens and Boivin 2006).

Male mating may also modify the behavior of conspecific males. Males are known to be choosy just like females (Wedell et al. 2002), and the females' mating status influences male choice. For example, the male preferences for virgin females and/or for females that they have never previously encountered have been observed in many insects species (Bonduriansky 2001; Wedell et al. 2002; Ferveur 2005; Bateman and Fleming 2006; Everaerts et al. 2010). Sexual pheromones transferred by males during mating can mark females as mated, making them less attractive to other males (Findlay et al. 2008). In Drosophila, mating induces changes in the female cuticular profile, which reduces the time spent in copulation by subsequent males (Friberg 2006; Everaerts et al. 2010). Previous mating can therefore influence the choice of other males, which generally prefer to mate with virgin females.

Because all the behavioral modifications detailed above do not require sperm transfer, such modifications are likely to occur after mating by a SDM. The aim of our study was thus 
to investigate the behavioral consequences of SDMs mating behavior in both sexes. In this system, conflict between the sexes arises, as females mated to a SDM are still unfertilized and so would gain by remaining attractive to other males in order to ensure egg fertilization. On the other hand, SDMs would gain by decreasing the attractiveness of the females they mated in order to reduce other males' opportunity to access them. Given that, we hypothesize that (i) females mated to a SDMs should be as receptive as virgin females in order to get access to further insemination, (ii) males should be more attracted to virgin females than females mated to a SDM and mated females.

To test these hypotheses, we used the parasitoid Asobara tabida Nees (Hymenoptera: Braconidae), a haplodiploid species in which sons result from unfertilized eggs while daughters result from fertilized eggs, allowing us to determine if the females had been successfully inseminated from the resulting sex ratio obtained - the presence of at least one daughter in the progeny is a proof of insemination. Asobara tabida males exhibit a stereotyped courtship behavior consisting of wing fanning, antennation, head movements, and leg tapping (Matthews 1975; Carton et al. 1986; Dufour et al. 2012). No postcopulatory behavior is reported for this species (Stökl et al. 2014). Asobara tabida males are generally sperm-depleted after a large number of matings (about 13 matings), but continue to mate after sperm depletion (Louâpre, Dufour, personal observation). Chemical communication is of great importance for mating as A. tabida males respond to chemicals deposited by females and increase their residence time in a patch previously exposed to females (Dufour et al. 2012). More recently, Stökl et al. (2014) highlighted the remarkable diversity of the sex pheromones of males and females in A. tabida. They showed that mating behavior in this species is regulated by a complex combination of chemicals rather than by a single molecule. 


\section{Insect rearing and general methods}

The Asobara tabida strain used in this study was collected in Chasse-Sur-Rhône (France, $\left.45^{\circ} 34^{\prime} \mathrm{N}, 4^{\circ} 48^{\prime} \mathrm{E}\right)$ in September 2008, and reared in the laboratory on second-instar Drosophila subobscura hosts in a controlled-climate room $\left(20^{\circ} \mathrm{C}, 60 \%\right.$ relative humidity, and 16:8 h Light:Dark). A few days before emergence, parasitized pupae from the culture were isolated in gelatin capsules $(0.68 \mathrm{~mL})$ to obtain virgin parasitoids of known age. Freshly emerged males and females were kept separately in plastic tubes $(\mathrm{h}=10 \mathrm{~cm}, \varnothing=2.5 \mathrm{~mm})$ and fed with diluted honey solution.

\section{Choice tests}

Experiments were performed in the controlled-climate room used for the rearing. Males were 1-2 days old and females were an equal mixt of 1-4 days old (the two females used in each if the choice test were of comparable ages in order to avoid potential confounding effect of age). A light table was used to maintain the individuals on the bottom of a Petri dish $(\varnothing=90 \mathrm{~mm})$ by phototaxis. All experiments were video-taped for a period of 15 minutes, and analyzed using the computer software package The Observer v3.0 (Noldus, Wageningen, The Netherlands). During each choice test, we noted (i) the male behavior (courtship, contact with the female, mating) (ii) the identity of the female toward which the male directed its behavior, and (iii) the behavior of the female toward the male (i.e. approaches and escapes, acceptance or rejection). The identity of the female toward which the first courtship was directed was also noted as a proxy of the male preference before any reaction from the female. Mating is indeed the result of both active and apparent choices of the two sexes and the first courtship give supplementary information compared to the mating with a given female (Martel and Boivin 2011). 
In this experiment, a virgin male was placed in the presence of both a female mated to a SDM and a virgin female in order to find out whether the male would perceive them as different resources. To obtain a female mated to a SDM, a single male mated a sequence of 30 virgin females over a period of 6 hours (from rank-1 to rank-30 females). Although Asobara tabida males become sperm-depleted after about 13 matings (Louâpre, Dufour, personal communication), we used females from rank-24 to rank-29 and we isolated the rank-23 and rank-30 females in a plastic tube containing a substrate of agar-nipagine and 20 second-instar D. subobscura larvae. The sex-ratio produced was noted, and only data from true SDMs and females mated to an actual SDM - whose offspring had a sex-ratio of 1 (i.e. male-only progeny) - were used for the analysis. In the rearing conditions, inseminated females indeed lay at least several females in a dozen of hosts, so that a male-only progeny obtained in 20 hosts is likely to be a strong clue for an absence of fertilization of the females. One female mated to a SDM (only females mated to different SDMs were used for each of the repetitions) and virgin female were then placed in the same clean Petri dish. A virgin male was introduced at the beginning of the experiment and placed equidistant from the two females. Thirteen dual choice tests were performed.

\section{Experiment 2: Female mated to the same SDM vs. virgin female}

In this experiment, each SDM was placed in the presence of a female he had previously mated without sperm transfer (randomly selected from rank-24 to rank 29 in the sequence of copulations) and a virgin female. Both the female mated to the SDM and the virgin female were placed in the same clean Petri dish. The SDM was introduced at the beginning of the experiment and placed equidistant from the two females. Eleven dual choice tests were performed. 
In this experiment, a fertile male was placed in the presence of a female he had previously mated and a female that had been mated by another male to determine whether males recognize a female they have previously mated. Ten minutes before the choice test, two virgin males each mated a virgin female in separate plastic tubes $(\mathrm{h}=10 \mathrm{~cm}, \varnothing=2.5 \mathrm{~mm})$. The two mated females were then placed in the same clean Petri dish. One of the two males used was introduced at the beginning of the experiment and placed equidistant from the two females. Twenty-two dual choice tests were performed.

\section{Statistical analyses}

Statistical analyses were performed using R 2.15.0 software at the critical level $\alpha=0.05$. The male choices were compared to a 50:50 probability (i.e. no preferential choice) using an exact binomial test. The mean numbers of the types of behavior exhibited by the males and females were analyzed using Wilcoxon tests. Because both virgin females and females mated to a SDMs were used in the first two experiments, the occurrence of approaches and escapes during these two experiments were analyzed by GLM-Poisson procedure, using the mating status of the females (i.e. virgin, pseudo-virgin, or mated) and of the males (fertile or spermdepleted) as factors. Multiple comparisons were then performed using the glht function of R (multcomp package).

\section{Results}

Experiment 1: female mated to a SDM vs. virgin female (fig. 1)

The two types of females exhibited the same number of approaches and escapes toward the virgin male (respectively $\mathrm{W}=82, \mathrm{P}=0.915$ and $\mathrm{W}=78, \mathrm{P}=0.753$ ) (fig. 1.b). Virgin males did not direct their first courtship or their first mating toward one female type rather than the 
other (Binomial test, respectively $\mathrm{P}=0.581$ and $\mathrm{P}=0.179$ ) (fig. $1 . \mathrm{a})$. During the course of the experiment, the males exhibited on average the same number of courtships and contacts with females mated to a SDM and virgin females (respectively, $\mathrm{W}=68, \mathrm{P}=0.401$ and $\mathrm{W}=64, \mathrm{P}=$ 0.288) (fig. 1.c). They tended to mate the originally virgin females more frequently than the SDM-mated females during the course of the experiment, but this difference was not significant probably due to the weak number of repetitions $(\mathrm{W}=52.5, \mathrm{P}=0.055)$ (fig. 1.c).

\section{Experiment 2: Female mated to the same SDM vs. virgin female (fig. 2)}

Virgin females exhibited more approaches toward the SDM than the females previously mated by him $(\mathrm{W}=26.5, \mathrm{P}=0.026)$, while the number of escapes from the SDM did not differ between both groups of females ( $\mathrm{W}=46, \mathrm{P}=0.352$ ) (fig. $2 . \mathrm{b})$. The first courtship was not significantly exhibited by SDMs toward one type of females over the other (Binomial test, $P=0.227$ ) (fig. 2.a). On average SDMs directed a similar number of courtships toward females mated by them and virgin females $(\mathrm{W}=35, \mathrm{P}=0.401)$ (fig. 2.c). However, they exhibited more contacts with virgin females than with females they previously mated $(\mathrm{W}=$ $29, \mathrm{P}=0.037$ ). They mated the virgin females before the females they previously mated (Binomial test, $\mathrm{P}=0.012$; fig. 2.a), and mated the originally virgin females more frequently than the SDM-mated females during the course of the experiment, even though she becomes mated after the first mating $(\mathrm{W}=13.5, \mathrm{P}<0.001$; fig. 2.c).

Experiment 3: Female previously mated by the same fertile male vs. female previously mated by another fertile male (fig. 3)

The two types of females exhibited the same number of approaches and escapes toward the fertile male ( $\mathrm{W}=299, \mathrm{P}=0.104$ and $\mathrm{W}=199, \mathrm{P}=0.313$, respectively) (fig. 3.b). Although fertile males directed their first courtship toward females previously mated by another male more often than toward the ones they had mated themselves (Binomial test, $\mathrm{P}=0.004$ ) (fig. 
3.a), they exhibited overall the same number of courtships and contacts toward both females $(\mathrm{W}=184.5, \mathrm{P}=0.171$ and $\mathrm{W}=211, \mathrm{P}=0.458$, respectively) (fig. 3.c). No mating was observed during this experiment.

Female behavior across the experiments (fig. $1 . b$ and 2.b)

The behavior of virgin females and females mated to a SDM was compared between experiments 1 and 2. The number of approaches by females differed depending on their mating status (GLM-Poisson, $\mathrm{F}_{1,80}=4.007, \mathrm{P}=0.045$ ), but not on the male mating status (GLM-Poisson, $\left.\mathrm{F}_{1,79}=0.442, \mathrm{P}=0.51\right)$ : females mated to a SDM exhibited more approaches than virgin females, regardless of the mating status of the males $(z=-1.997, P=0.046)$. The number of escapes differed between females, but differently depending on the mating status of the male (GLM-Poisson, female mating status: male mating status, $\mathrm{F}_{3,78}=2.992, \mathrm{P}=$ 0.029): females mated to a SDM exhibited the same number of escapes from virgin males and SDMs $(z=-0.205, P=0.997)$, while virgin females exhibited more escapes from SDMs than virgin males $(\mathrm{z}=2.624, \mathrm{P}=0.043)$.

\section{Discussion}

We showed that (i) virgin females, mated females, and females mated to a SDM exhibited different behaviors, and that (ii) the mating status of the females influences the behaviors of males. Different behaviors were observed according to the reproductive status of the two sexes, although the majority of the females were of the same mating status at the end of the experiment. As pointed out by Martel and Boivin (2011), mating depends not only on the choice of the individual (true choice), but also on the response of the partner (apparent choice). Accordingly, we showed that the mating pattern in this species can be influenced by the SDM's behavior, which in turn impacts both males' and females' choice. Our results thus demonstrate that SDMs influenced the male responsiveness and female attractiveness. 

have mated and virgin females. Females mated to a SDM were more attracted to males than virgin females whatever the reproductive status of the males. Moreover, virgin females exhibited more escapes from SDMs than from virgin males. Taken together, these findings show that (i) females mated to a SDM were more reproductively active than virgin females, and that (ii) SDMs are not as attractive for females as virgin males. Females mated to a SDM should be as least as active as virgin females in order to compensate for the unsuccessful insemination (Arnqvist and Nilsson 2000; Hosken et al. 2001; Chapman et al. 2003; Tregenza et al. 2006). Our results are consistent with this and demonstrate that even if SMDs transferred seminal fluid to the females, this did not inhibit female sexual receptivity as it was demonstrated for other species (Leopold 1976; Avila et al. 2011). Female A. tabida mated to a SDM are thus receptive to mating, as has been shown for females Trichogramma evanescens mated to a SDM (Damiens and Boivin 2006). Moreover, females mated to a SDM seemed to exhibit adaptive behavior, because they reduced the number of approaches they made toward SDMs; whatever the mechanism behind this post-mating effect, females mated to a SDM (reviewed by Rhainds 2010). other types of behavior exhibited by females in order to ensure that their eggs are fertilized

The behavior of males is also influenced by the reproductive status of the females; virgin females, females mated by a SMD and mated females do not elicit the same behavioral response from males according to the mating status of the males. Our results did not show any significant effect of the reproductive status of the females on the behavior of virgin males (experiment 1). We however noted a tendency of virgin males to exhibit their first courtship and mating toward virgin females, and the small sample size could have led to non-significant results. SDMs, however, did exhibit their first courtship and mating toward virgin females 
over females they previously mated. They also exhibited more contacts toward virgin females over females they mated (experiment 2). These results demonstrate that females mated to a SDM are not perceived as virgin females by the males. The preferential choice of SDMs for virgin females rather than females mated to a SDM - even though females mated to a SDM continue to be receptive to mating - suggests a decrease in the attractiveness of females mated to a SDM.

Many cues can be used by males to discriminate between virgin females and females mated to a SDM, and chemicals must play a major role (Thomas 2011). In bumblebees and parasitic wasps, sexual pheromones are indeed known to carry information about mating status (Lloyd 1981; Ode et al. 1995). In Drosophila, the cuticular profiles of females change after mating (Steiger et al. 2008). Moreover, the mating behavior of Asobara tabida - like many other insect species - is based on a complex and dynamic infochemical emission, and on the perceptions of both males and females (Stökl et al. 2014). Asobara tabida males may thus perceive and respond to chemical changes in the mated females (with or without sperm being stored), which enable them to discern the female's reproductive status.

Males could be more attracted to virgin females than to females mated to a SDM because they never encountered the virgin females they faced with (the so-called 'Coolidge effect') (Wilson et al. 1963; Dewsbury 1981). Based on individual marking recognition, Steiner et al. (2008) have shown that males of the burying beetle Nicrophorus vespilloides Herbst (Coleoptera: Silphidae) use female cuticular patterns to discriminate between novel females and those they have previously inseminated. In our study, such a "Coolidge effect" may be responsible for the choice of males faced by two mated females (experiment 3), and the choice of a SDM facing virgin females and females mated to a SDM (experiment 1), but not for that of virgin males in the first experiment. Indeed, the virgin males used in our study had never encountered any females. The change in the behavior of the males and females may 
therefore involve different mechanisms, and do not depend on sperm transfer.

To conclude, our study showed that the mating process in A. tabida depends on the

262 behavior of both sexes, and is not a simple and unidirectional choice of one sex toward the

263 other. Asobara tabida males thus actively choose their mates on the basis of mating status, but

264 females can accept or reject the interested males. SDMs and females mated to a SDM behave

265 in different ways towards fertile males, and virgin or mated females, respectively. As other

266 authors have suggested, the modification of male and female behavior as a result of mating

267 could be a way of improving the fitness of SDMs (Damiens and Boivin 2006) by decreasing

268 the likelihood of subsequent mating by other males through sperm competition avoidance.

269 Many hypotheses have been advanced to explain the female mating failure in nature,

270 including a lack of opportunity for mating (Rhainds 2010). The mating behavior of SDMs

271 may contribute to this phenomenon by making females mated to a SDM look like successfully

272 mated females to other males. 
274 Acknowledgments

275 We are grateful to Elise Blondelot and Myriam Labrecque for their technical helps, and 276 Monica Gosh for English revision. This research was supported by a grant from the Ministère

277 de l'Enseignement Supérieur et de la Recherche. All experiments conducted in this study 278 comply with the current animal experimentation regulations in France. 


\section{References}

Alcock J (1994) Postinsemination associations between males and females in insects: the mate-guarding hypothesis. Ann Rev Entom 39:1-21. doi: 10.1146/annurev.en.39.010194.000245

Arnqvist G, Nilsson T (2000) The evolution of polyandry: multiple mating and female fitness in insects. Anim Behav 60:145-164. doi: 10.1006/anbe.2000.1446

Assem J Van Den, Gijswijt MJ, Nübel BK (1979) Observations on courtship - and mating strategies in a few species of parasitic wasps (Chalcidoidea). Netherlands J Zool 30:208227.

Avila FW, Sirot LK, LaFlamme BA, et al. (2011) Insect seminal fluid proteins: identification and function. Annu Rev Entomol 56:21-40.

Bateman PW, Fleming PA (2006) Males are selective too: mating, but not courtship, with sequential females influences choosiness in male field crickets (Gryllus bimaculatus). Behav Ecol Sociobiol 59:577-581. doi: 10.1007/s00265-005-0083-y

Boivin G (2013) Sperm as a limiting factor in mating success in Hymenoptera parasitoids. Entom Exp App 146:149-155. doi: 10.1111/j.1570-7458.2012.01291.x

Bonduriansky R (2001) The evolution of male mate choice in insects: a synthesis of ideas and evidence. Biol Rev 76:305-339. doi: 10.1017/S1464793101005693

Carton Y, Bouletreau M, Van Alphen JJM, Van Lenteren JC (1986) The Drosophila parasitic wasps. Genet. Biol. Drosoph., M Ashburne. Academic Press, New York, pp 347-394

Chapman T, Arnqvist G, Bangham J, Rowe L (2003) Sexual conflict. Trends Ecol Evol 18:41-47.

Damiens D, Boivin G (2006) Why do sperm-depleted parasitoid males continue to mate? Behav Ecol 17:138-143. doi: 10.1093/beheco/arj009

Damiens D, Boivin G (2005) Male reproductive strategy in Trichogramma evanescens: sperm production and allocation to females. Physiol Entomol 30:241-247. doi: 10.1111/j.13653032.2005.00453.x

Dewsbury DA (1981) Effects of novelty of copulatory behavior: The Coolidge effect and related phenomena. Psych Bull 89:464-482. doi: 10.1037/0033-2909.89.3.464

Dufour CM-S, Louâpre P, van Baaren J, Martel V (2012) When parasitoid males make decisions: information used when foraging for females. PLoS One 7:e46706. doi: 10.1371/journal.pone.0046706

Ejima A, Smith BPC, Lucas C, et al. (2007) Generalization of courtship learning in Drosophila is mediated by cis-vaccenyl acetate. Curr Biol 17:599-605. doi: 10.1016/j.cub.2007.01.053 
Everaerts C, Farine J-P, Cobb M, Ferveur J-F (2010) Drosophila cuticular hydrocarbons revisited: mating status alters cuticular profiles. PLoS One 5:e9607. doi: 10.1371/journal.pone.0009607

Ferveur J-F (2005) Cuticular hydrocarbons: their evolution and roles in drosophila pheromonal communication. Behav Genet 35:279-295. doi: 10.1007/s10519-005-3220-5

Findlay GD, Yi X, MacCoss MJ, Swanson WJ (2008) Proteomics reveals novel Drosophila seminal fluid proteins transferred at mating. PLoS Biol 6:e178. doi: 10.1371/journal.pbio.0060178

Friberg U (2006) Male perception of female mating status: its effect on copulation duration, sperm defence and female fitness. Anim Behav 72:1259-1268. doi: 10.1016/j.anbehav.2006.03.021

Gillott C (2003) Male accessory gland secretions: modulators of female reproductive physiology and behavior. Ann Rev Entom 48:163-184. doi: 10.1146/annurev.ento.48.091801.112657

Gordh G, DeBach P (1976) Male inseminative potential in Aphytis lingnanensis (Hymenoptera: Aphelinidae). Can Entomol 108:583-589.

Hosken DJ, Garner TWJ, Ward PI (2001) Sexual conflict selects for male and female reproductive characters. Curr Biol 11:489-493.

Laing D, Caltagirone L (1969) Biology of Habrobracon lineatellae (Hymenoptera: Braconidae). Can Entomol 101:135-142.

Leopold R (1976) The role of male accessory glands in insect reproduction. Annu Rev Entomol 21:199-221.

Lloyd JE (1981) Sexual selection: individuality, identification, and recognition in a Bumblebee and other insects. The Florida Entom 64:89. doi: 10.2307/3494603

Martel V, Boivin G (2011) Do choice tests really test choice? J Insect Behav 24:329-336. doi: 10.1007/s10905-011-9257-9

Matthews RW (1975) Courtship in parasitic wasps. Evol. Strateg. Parasit. insects mites. Springer, pp 66-86

Nadel H, Luck R (1985) Span of female emergence and male sperm depletion in the femalebiased, quasi-gregarious parasitoid, Pachycrepoideus vindemiae (Hymenoptera: Pteromalidae). Ann Entomol Soc Am 78:410-414.

Ode PJ, Antolin MF, Strand MR (1995) Brood-mate avoidance in the parasitic wasp Bracon hebetor Say. Anim Behav 49:1239-1248. doi: 10.1006/anbe.1995.0156

Olsson M, Madsen T, Ujvari B, Wapstra E (2004) Fecundity and MHC affect ejaculation tactics and paternity bias in sand lizards. Evol 58:906-909. 
Pizzari T, Cornwallis CK, Løvlie H, et al. (2003) Sophisticated sperm allocation in male fowl. Nature 426:70-74. doi: 10.1038/nature02004

Preston BT, Stevenson IR, Pemberton JM, Wilson K (2001) Dominant rams lose out by sperm depletion. Nature 409:681-682. doi: 10.1038/35055617

Radhakrishnan P, Pérez-Staples D, Weldon CW, Taylor PW (2009) Multiple mating and sperm depletion in male Queensland fruit flies: effects on female remating behaviour. Anim Behav 78:839-846. doi: 10.1016/j.anbehav.2009.07.002

Ramadan MM, Wong TT., Wong MA (1991) Influence of parasitoid size and age on male mating success of opiinae (Hymenoptera:Braconidae), larval parasitoids of fruit flies (Diptera:Tephritidae). Biol Control 1:248-255. doi: 10.1016/1049-9644(91)90074-A

Rhainds M (2010) Female mating failures in insects. Entom Exp App 136:211-226. doi: 10.1111/j.1570-7458.2010.01032.x

Rönn JL, Katvala M, Arnqvist G (2008) Interspecific variation in ejaculate allocation and associated effects on female fitness in seed beetles. J Evol Biol 21:461-470. doi: 10.1111/j.1420-9101.2007.01493.x

Rubolini D, Galeotti P, Pupin F, et al. (2007) Repeated matings and sperm depletion in the freshwater crayfish Austropotamobius italicus. Freshw Biol 52:1898-1906. doi: 10.1111/j.1365-2427.2007.01814.x

Simmonds F (1953) Observations on the biology and mass-breeding of Spalangia drosophilae Ashm (Hymenoptera, Spalangiidae), a parasite of the frit-fly, Oscinella frit (L.). Bull Entomol Res 44:773-778.

Smith C, Pateman-Jones C, Zięba G, et al. (2009) Sperm depletion as a consequence of increased sperm competition risk in the European bitterling, Rhodeus amarus. Anim Behav 77:1227-1233.

Steiger S, Franz R, Eggert A-K, Müller JK (2008) The Coolidge effect, individual recognition and selection for distinctive cuticular signatures in a burying beetle. Proc R Soc B 275:1831-1838. doi: 10.1098/rspb.2008.0375

Steiner S, Henrich N, Ruther J (2008) Mating with sperm-depleted males does not increase female mating frequency in the parasitoid Lariophagus distinguendus. Entom Exp App 126:131-137. doi: 10.1111/j.1570-7458.2007.00641.x

Stökl J, Dandekar A-T, Ruther J (2014) High chemical diversity in a wasp pheromone: a blend of methyl 6-methylsalicylate, fatty alcohol acetates and cuticular hydrocarbons releases courtship behavior in the drosophila parasitoid Asobara tabida. J Chem Ecol 40:159-168. doi: 10.1007/s10886-014-0378-4

Thomas ML (2011) Detection of female mating status using chemical signals and cues. Biol Rev 86:1-13. doi: 10.1111/j.1469-185X.2010.00130.x 
Tregenza T, Wedell N, Chapman T (2006) Introduction. Sexual conflict: a new paradigm? Phil Trans R Soc B 361:229-234. doi: 10.1098/rstb.2005.1796

Wedell N (2005) Female receptivity in butterflies and moths. J Exp Biol 208:3433-3440. doi: $10.1242 / \mathrm{jeb} .01774$

Wedell N, Gage MJG, Parker GA (2002) Sperm competition, male prudence and spermlimited females. Trends Ecol Evol 17:313-320. doi: 10.1016/S0169-5347(02)02533-8

Wilson JR, Kuehn RE, Beach FA (1963) Modification in the sexual behavior of male rats produced by changing the stimulus female. J Comp Physiol Psychol 56:636-644.

Yamane T (2013) Reduction of female mating receptivity after injection of male-derived extracts in Trigonotylus caelestialium (Heteroptera: Miridae). Ann Entomol Soc Am 106:258-264. doi: 10.1603/AN12079 


\section{Figure legends}

Figure 1: Behaviors of virgin males $(a, b)$, virgin females and females mated to a SDM (c) during the first experiment. (a) Proportion ( $\pm 95 \%$ confidence interval) of virgin males exhibiting their first courtship toward (top, $n=13$ ) and/or mated first with (bottom, $n=9$ ) the proposed females. (b) Mean number $( \pm \mathrm{SE})$ of behavior exhibited by virgin males toward different types of females. (c) Mean number $( \pm$ SE) of behavior exhibited by females toward virgin males. (ns.: not significant).

Figure 2: Behaviors of SDMs $(a, b)$, virgin females and females mated to the same SDM (c) during the second experiment. (a) Proportion ( $\pm 95 \%$ confidence interval) of SDMs exhibiting their first courtship toward (top, $\mathrm{n}=11$ ) and/or mated first with (bottom, $\mathrm{n}=11$ ) the proposed females. (b) Mean number $( \pm$ SE) of behavior exhibited by SDMs toward different types of females. (c) Mean number $( \pm$ SE) of behavior exhibited by females toward the SDM. (ns.: not significant; $* \mathrm{P}<0.05$ ).

Figure 3: Behaviors of fertile males (a, b), females mated to the same male or to another male (c) during the second experiment. (a) Proportion ( $\pm 95 \%$ confidence interval) of fertile males exhibiting their first courtship toward $(n=22)$ the proposed females. (b) Mean number $( \pm$ SE) of behavior exhibited by the SDM toward different types of females. (c) Mean number $( \pm \mathrm{SE})$ of behavior exhibited by females toward the SDM. (ns. not significant; $* * \mathrm{P}<$ $0.01)$ 
$418 \quad$ Figures

$419 \quad$ Figure 1

420 Les paramètres nécessaires sont manquants ou erronés.

421 
$422 \quad$ Figure 2

423 Les paramètres nécessaires sont manquants ou erronés.

424 
$425 \quad$ Figure 3

426 Les paramètres nécessaires sont manquants ou erronés. 